\title{
22
}

\section{Chief Information Officers - new roles and emerging duties}

\author{
Mikko J. Ruohonen
}

Docent and Acting Professor of Information Systems Science, Director of Executive Education Institute Turku School of Economics and Business Administration P.O. Box 110, FIN-20521 TURKU, FINLAND.

\begin{abstract}
Strategic and organisational factors are driving the decentralisation of computing power. Starting from the distribution of hardware and later on of some applications development, we are now facing the decentralisation of IS decision and coordination power.

These changes affect the roles and duties of Chief Information Officers (CIOs). CIOs have traditionally governed the use of information resources, but under current business conditions they need to agree on the division of different IS tasks and the distribution of decision power.

This paper evaluates the transformation of IS-related work and future challenges in the context of IS management. The role of the CIO is regarded more as that of mentor, coach and counsellor for service-oriented IS organisations. Internal consultancy is needed more in the light of growing IS costs and reliance on operative information systems. In addition, CIOs need to play with different stakeholders, guarantee the validity of joint IS resources and act as an ambassador for their business.

Furthermore, we need more research on the organisational evolution of IS and the changes in IS-related work. Many of the development tasks are no longer just IS development or IS operations. They are, increasingly, embedded in changes in the organisation, work activities, control structures and customer and alliance operations. Information systems are actually part of business processes.

Internal integration of the IS workforce is needed to cope with external adaptation needs due to changing business competition. CIOs have to make these decisions and hence become mediators of business turbulence and provided IS services.
\end{abstract}

Chief Information Officers, Roles

Keywords 
The importance of information systems (IS) has shifted from pure atomisation and cost efficiency towards the need to transform organisations (Zuboff 1988, Scott-Morton 1991). The voluminous research and writings about the competitive advantages of information technology (IT) (McFarlan 1984, Cash \& Konsynsky 1985, Cash et al. 1988) preceded the current discussion about business process redesign or improvement (Davenport 1993). They consider information and the management of information resources critical for business success. IT evolution affects the transformation of work (Sachs 1995), relationship management (Iacono et al. 1995) and the stakes of different organisational groups (Ruohonen 1991, 1995). Planning, organisation and control of information resources and management of information technology, i.e. information management as defined by Earl (1989), is a serious managerial responsibility, which should be integrated with managerial practice and foster the formation of the organisation's IS plans, generally termed an information strategy.

A rationale for emerging information management duties is found in the evolution of ISrelated work (Keen 1988). Almost all IS duties were mainly the job of IT/IS professionals, due to IS's technical nature and primary value as a support function. The value of IT/IS to organisations increased and IS planning became a matter of business knowledge, due to profound effects on business operations, competition and the structure of industry. Now IS planning issues have also shifted to being the responsibility of general and business managers. Managers need new competencies and the hybridisation of managerial knowledge is inevitable; but this is not the final solution. It has been noted that creating hybrid managers is not sufficient to develop a meaningful partnership between IS and the business (Earl \& Skyrme 1990 \& 1992 Lodahl \& Redditt 1989, Dixon \& John 1989, Hartog \& Rouse 1987). Therefore we need cooperation and understanding of different views, which leads us to relationship management issues. Information strategy teams require critical organisation decision-makers, while many of the IS development projects need a lot of resources. Now, we very often face an organisational situation where the contribution of the DP manager has moved from back-room EDP departments to the daily service and customer operations, and his/her role has grown into something we call as Chief Information Officer (originated by Synnott \& Gruber 1981).

The objective of this paper is to examine the role of the CIO and what kind of duties the evolution of IS-related work in organisations has brought to this new breed of IS professionals.

\section{THE IDEAL CHIEF INFORMATION OFFICERS}

\subsection{Background; different roles and emerging needs}

It is clear that changing work requirements in the current use of IT in organisations also affect ideal attributes of Chief Information Officers. It has also been noted that external pressures, such as the growing turbulence of business environments and internal pressures, such as the questioning of large and growing IT departments by senior managers, have made managing the IS/IT function one of the most vulnerable management positions in an organisation (Land 
1995). Both practitioners (Lodahl \& Redditt 1989, Dixon \& John 1989, Moad 1994) and academics (Grover et al. 1993, Stephens 1995) have noticed the changing arena of needs for CIOs that has now been topic of research over ten years (Rockart et al. 1982). It means that CIOs' responsibility has increased tremendously, although their real decision making power may be minimal. CIO's role in driving and coordinating IS activities is quite crucial, while it has also been noted that managerial IT knowledge is a significant determinant of IT use i.e. the application of IT within an organisation's operational and strategic activities (Boynton et al. 1994).

Keen (1988) comments that IS professionals' work and career development have been based on tasks rather than on roles. Keen divides his career trajectory of future IS professionals into two dimensions: (i) technical; consisting of breadth of experience and currency of specialisation and ii) business/organisational; consisting of business/ functional knowledge and organisational skills. These dimensions can be defined into four role categories as follows:

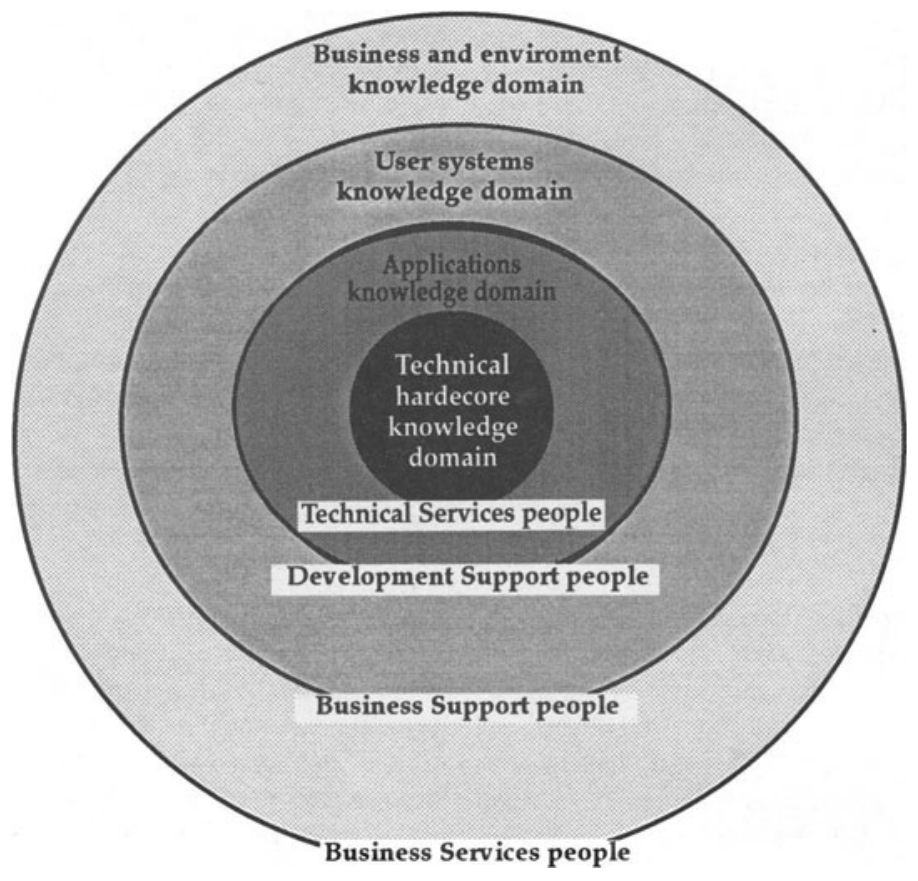

Figure 1 Four roles of IS professionals and their linkages in the context of evolving use of IT in organisations (modified from Keen 1988).

Development Support people are able to communicate with the users or customers of the organisation. They should have good communication skills - both output and input. They also face a need to handle large projects where they have to deal with different stakeholders. Information systems are built in co-operation with technical IS people. 
Business Support people require strong business knowledge and organisational expertise. They very often work with new and emerging technologies where the innovative use of IT is more important than the strict operationalisation of systems projects. Good examples are office automation, end-user computing, multimedia, the Internet and business-based IS deliveries.

Technical Services people should concentrate on the management of technical excellence. Many of the large-scale projects of organisations require a good knowledge of IS architectures and network configurations. They should also guarantee operations services in those industries where information systems are critical for business operations.

Business Services people are those who deal with business and IS planning, and provide portfolio level plans for business units. They should also have financial and other evaluation knowledge and skills in order to measure and compare the performance of IT. Business services people should control vendor relationships, too.

\subsection{Hybrid managers; a solution?}

Hybridisation and "hybrid people" have usually been proposed as a solution to the need for cross-disciplinary expertise and cross-task knowledge. Earl and Skyrme $(1990,1992)$ have defined hybrid managers' key roles as follows:

- enhance business orientation of IT by increasing IT specialists' awareness of business opportunities.

- enhance IT capabilities by increasing awareness and responsiveness to different business needs, by constant retooling of IT infrastructure, continual honing of IT skills and professionalism and by appropriate selection and use of specialist skills.

- enhance organisation's understanding of IT by refocussing the organisation to understand IT, educating and consulting on strategic use of IT and reinforcing IT's benefits and potential to business managers.

- build successful IS/business partnerships by developing shared vision of entire business, sharing responsibility for projects between IT and the business and helping line managers make IT decisions.

The majority of these issue are related to Business Services and Business Support. The whole professional area and related knowledge has enlarged from hard-core, technical issues towards soft, communications and people-oriented issues. If we accept this, it puts great pressure on Chief Information Officers and their development. On the one hand they face growing business development challenges and on the other they should transform personnel's orientation and service attitudes and keep the organisation running in top gear. Keen (1988) summarises that the main career directions for IS professionals are towards Development Support and Business Support; for those whose training has followed a mostly technical path, it is hard to transform. However, he comments that there is no room for average technicians.

\subsection{New challenges of $\mathrm{CIO}$ work}

This reflects the background for the evolution and new requirements of IS professional work. What will be the role and responsibilities of the CIO in the current organisational context? This 
is very much related to decision maker power and the organisational position of CIOs. Stephens and her colleagues (Stephens et al. 1994, Stephens 1995) have studied the role of the CIO quite extensively. She found, for example, that the industry's present and anticipated competitiveness affects the CIO's participation in strategy planning. This is well in line with the latest studies on environmental business turbulence and strategic IS planning (Salmela 1996). It may be that the company functions in an environment where there is not so much use of strategy level IS planning i.e. there is no need for the IS manager or CIO to participate. However, competitiveness is not all; Stephens (1995) argues that we also need the personal and political acceptance of senior management for the CIO to participate in strategic planning and the authority to approve or deny IT expenditures. Hence, internal organisational politics, corporate culture and the way of appreciating IS activities affect the role and responsibilities of CIOs as also noted by Earl \& Skyrme (1990) and (1992). This is also linked to each CIO's personal characteristics and education. Authority to approve or deny IT expenditures is related to the organisational process of information resource management i.e. how it is organised and what the power relationships are to other critical stakeholders such as the CEO and business unit management (Rockart 1988, Boynton et al. 1992, Ruohonen 1991, 1995). This depends on whether the organisational information management strategy (Reponen 1994) is accepted as an organisation-wide transformational element with IS power allocation and control mechanisms. Previously, the traditional DP manager's role was to initiate IS projects, act as a foreman of IS personnel and negotiate with IT vendors. Now, the CIO's role and responsibilities are much wider. They must come out of their offices, follow the IT industry and vendor discussion, compare the opportunities to the needs of their company, acquire competent staff and education, discuss with business management and provide IS services to front-end operations. They are increasingly internal consultants of business-critical IS evolution, no longer just EDP bureaucrats.

In my view the following large job groups, the new challenges of our times, will inevitably be managed in the current and future work context of CIO.

- Business process redesign, outsourcing and decentralisation

- IT architecture development

- IS organisation transformation

- Information management principles creation

- Human resource development

- Vendor management

\section{Business process redesign, outsourcing and decentralisation}

The decentralisation of information resources to business units and the down-sizing of large IS infrastructures have been highly typical phenomena in the last ten years. The growing business independence of business units and their needs to serve customers better and more accurately has forced centralised IS Departments to decentralise both technical and human resources in order to maintain and develop the IS of the business units. Business transformation drives IS development, while in many of the companies IT plays a very operative role.

In business units the CIO's role is to guarantee that by personnel selection and their own coordination, business unit managers are satisfied both with their own internal IS and centralised IS services. This means that at the business unit level communications and understanding of business issues come first followed by project management and applications 
knowledge. The CIO's role is to coordinate, create justified cost estimates and provide a general overlay of how the IS of the whole organisation should be organised. At the corporate level they must solve problems related to different stakeholder stances.

Outsourcing IS activities is not generally solution to IS problems. Organisations need to be careful in analysing which activities are ready for outsourcing, e.g. training activities or data processing services, and which should be handled internally, e.g. business process management or strategy control. CIOs should focus on rightsourcing which is the objective after the outsourcing and insourcing era.

\section{IT architecture development}

The information technology architecture of the company can vary from "an applications jungle" to a deliberately created technology platform. This is one of the most challenging responsibilities of the CIO. Without a working IT architecture, IS development at least but perhaps also business evolution are inferior and will not face up to the challenges of the business environment. Many IT architectures include a heavy telecommunications and networking sub-architecture which should fit not only with the internal IS but also with the IS of partners, suppliers, customers etc. Planning therefore becomes more complicated and a lot of visionary intuition is needed. In the case of conglomerates that normally grow by acquisition it is very hard to merge different kinds of IS. However, internal growth can also be too fast for IT architecture development, so some technology leaps are necessary to maintain a flexible IT architecture from four to seven years. IT architecture can otherwise become a technology burden.

\section{IS organisation empowerment and management}

Quite a few IS organisations, at least in-house ones, are too often old-fashioned and rigid line organisations. This is true particularly of organisation charts. However, IS/IT people are experts and many IS development issues are set up in projects that ruin the organised picture. The organisation itself is very much a network; only the more stable parts of the IS organisation, such as Operations or End-User Support, can be organised hierarchically. The other parts which are evolving and in many cases fire-fighting IS problems should be organised on a self-steering principle. People management skills are very important to a competent CIO. They should give more decision power to their subordinates and rely on their expertise. One of the biggest mistakes is to try and do everything by yourself, to try control everything. This very quickly leads to a low service-level, project delays and unfavourable internal work culture.

\section{Information management principles creation}

Information management strategy is a conscious statement that should manifest the agreed IS needs across the organisation and provide an overall view of IS development, IT architecture and IS organisation for the coming five years. It should also comment on decision making and power allocation mechanisms. This means defining the reporting relationships of the CIO, the decision making level concerning for IS investments, IS development responsibilities in the user organisation, joint principles concerning internal software and hardware standards and the evaluation and cost-justification of IS organisation.

IS departments often work as cost-centers where all the costs are budgeted as centralised overheads. This very often leads to a situation where independent business units compete for 
joint resources. If coordination principles are absent, CIOs have to follow the most powerful department or unit, very often the Accounting Department. On the other hand, if the IS Manager is subordinate to Chief Administrative or Finance Officer, there is a danger that, e.g. the Marketing Department will get minimal IS resources and support due to the proliferation of administrative IS projects. In recent years it has been common to nominate the CIO as a VicePresident level executive who preferably works as a member of the Board of Directors. However, research has shown that this is not a sufficient condition while, for example, a physical distance between the CEO and CIO can correlate to the success of IS (Feeny et al. 1992). It might be said that it is not enough to change the title of the EDP Manager to CIO, if there are no changes in power relationships and IS investments. The CIO's role and power are therefore related to the general competitive importance of IT in industry at present and the internal awareness of an organisation's key management.

\section{Human resource development}

The CIO's human resource management responsibilities are to select competent people, organise the work activities of their personnel in order to answer the needs of business unit users, provide services on time and to make sure that proper further training is provided and that career opportunities are motivating.

This makes the CIO the mentor or coach of the team that "tries harder". Naturally, the CIO needs professional help from Human Resources people which may also cause organisational problems. Human Resource people coming from a behavioural or training background may have first phase problems in understanding the knowledge and skill profiles of the required IS people. In many cases, they must rely solely on the CIO's views. There is, however, a danger that the CIO cannot see the behavioural issues of personnel selection as being important and will emphasise technical competencies (Couger 1988). This is further complicated when, for example, a top IT expert in telecommunications who is at the same time socially incompetent can cause problems in a needs definition phase. However, if you have a position that is quite isolated and related just to high-tech issues, and rather than human ones (e.g. many production control systems jobs), there is no need to worry about social skills. In the work organisation, the CIO needs help for work activity transformation and training for users and IS/IT people should be organised in a systematic way.

\section{Vendor management}

Earlier it was both quite common and rather unfortunate that vendors formulated the IS strategies of their customer organisations. At that time IT architectures were based on closed systems over the building of which vendors held quite a lot decision power. Those systems often missed the business issues of an organisation and relied quite heavily on technology platforms.

Now that business is driving IT, and competition in the open markets of information technology is increasing, CIOs need technology purchasing knowledge more than ever. They should be aware of the newest applications, but more importantly need to have expertise to effectively compare different options and create a real competition arena for different vendors. However, they should not sacrifice long-term service benefits and should also be aware of innovative ways to organise IS services, e.g. by outsourcing and/or buying IS services. 
CIOs are regarded more as mentors, coaches and counsellors for service-oriented IS organisations. Internal consultancy is increasingly needed in situations of growing IS costs and reliance on operative information systems. The CIO needs to communicate with different organisational stakeholders, guarantee the validity of joint IS resources and act as an internal marketing officer for their business.

\section{CONCLUDING REMARKS}

The literature review and documented experiences support the idea of new, emerging roles and duties for CIOs. Obviously these roles and duties are very much related to the qualities of those industries in which CIOs are working. Furthermore, the situation can also change according to different national cultures and economies. Technology platforms naturally drive the evolution, but some organisations can survive without constant updating of IT. So, even IT evolution is not necessarily determining the growth needs of CIOs, while the success of the CIO is mostly dependent on aligning business needs and IT opportunities.

It seems that more research is needed on at least two issues. First, we need more IS curriculum planning that does not restrict its educational content in the spirit of the dual career -idea (i.e. technical vs. business, see Ginzberg \& Baroudi 1988). Many of the current and future development projects are cross-functional, cross-disciplinary and cross-cultural endeavours. In addition to technology and business knowledge, CIOs need organisational, behavioural and cultural learning. Future CIOs need multiple qualities.

Secondly, we need more research on IS organisations and IS work-task evolution. This implies the growing use of organisation and management theory in the context of new expert organisations. As one of the latest research findings (Boynton et al. 1994) suggests besides IT managerial knowledge, the IT management climate is related to actual IT use. Boynton and his colleagues (1994) proposed, therefore, a more organic rather than mechanistic IT management climate. As bosses of their IT specialists and critical mediators of organisational evolution CIOs need more conceptually and empirically valid tools and approaches.

Future research should increasingly observe the role of the CIO as a mediator between external business turbulence and the management of IS services. This should be executed in the light of both the needs of internal integration, i.e. what is happening inside the IS organisation and external adaptation, i.e. what is needed in the context of changing business environment.

\section{REFERENCES}

Boynton, A.C., Jacobs, G.C. and Zmud, R.W. (1992) Whose Responsibility Is IT Management. Sloan Management Review, Summer, pp. 32-38.

Boynton, A.C., Zmud, R.W. and Jacobs, G.C. (1994) The Influence of IT Management Practice on IT Use in Large Organisations. MIS Quarterly 18 (3), pp. 299-318.

Cash, J. \& Konsynsky, B. (1985) "IS Redraws Competitive Boundaries". Harvard Business Review 63 (2) pp. 134-142. 
Cash, J., McFarlan, F.W. \& McKenney, J.L. (1988), Corporate information systems management - issues facing senior managers. Dow Jones Irwin, Homewood, IL, 2rd edition.

Couger, J.D. (1988) Key Human Resource Issues in IS in the 1990's: Views of IS Executives versus Human Resource Executives. Information \& Management 14, pp. 161-174.

Dixon, P.J. \& John, D.A. (1989) Technology Issues Facing Corporate Management in the 1990's. MIS Quarterly 13(3), pp. 247-256.

Earl, M.J. (1989) Management strategies for information technology. Prentice-Hall, Cambridge.

Earl, M.J. \& Skyrme, D.J. (1990) "Hybrid Managers": What Do We Know About Them? Research and Discussion Papers 1990/6, Oxford Institute of Information Management, Oxford.

Earl, M.J. \& Skyrme, D.J. (1992) Hybrid Managers. Journal of Info Systems 2, pp. 169-187.

Feeny, D.F., Edwards, B.R. \& Simpson, K.M. (1992) Understanding the CEO/CIO Relationship. MIS Quarterly 16 (4), pp. 435-448.

Ginzberg, M.J. \& Baroudi, J.J. (1988) MIS Careers - A Theoretical Perspective. Communications of the ACM 31 (5), pp. 586-594.

Grover, V., Jeong, S-R., Kettinger, W.J. \& Lee, C.C. (1993) The Chief Information Officer: A Study of Managerial Roles. Journal of Management Information Systems 10(2), pp. 107130.

Hartog, C. \& Rouse, R.A. (1987) A Blueprint for the New IS Professional. Datamation, Vol. 33 , October 15 , pp. 64-69.

Iacono, C.S., Subramani, M. \& Henderson, J. (1995) Entrepreneur or Intermediary: The Nature of the Relationship Manager's Job. Proceedings of the 16th International Conference on Information Systems (ICIS), Amsterdam, The Netherlands, December 1013, pp. 289-299.

Keen, P.G.W. (1988) Roles and Skill Base for the IS Organisation. In Elam, J.J., Ginzberg, M.J., Keen, P.G.W. \& Zmud, R.W. (1988) Transforming the IS Organisation. ICIT Press, Washington., pp. 17-40.

Land, F. (1995) The New Alchemist: or How to Transmute Base Organisations into Corporations of Gleaming Gold. Viewpoint of the Conference Chairman. In Doukidis, G., Galliers, B., Jelassi, T., Krcmar, H. \& Land, F. (eds) Proceedings of the Third European Conference on Information Systems, Athens, Greece, June 1-3, 1995, pp. 21-29.

Lodahl, T.M. \& Redditt, K.L. (1989) Aiming IS at Business Targets. Datamation 35 (4), pp. 93-100.

McFarlan, F.W. (1984) Information technology changes the ways you compete. Harvard Business Review 62 (3) pp. 98-103.

Moad, J. (1994) Wanted: The Multithreaded CIO. Datamation, April 15, pp. 34-38.

Rockart, J.F., Ball, L. \& Bullen, C.V. (1982) Future Role of the Information Systems Executive. MIS Quarterly, Special Issue, pp. 1-14.

Rockart, J.F. (1988) The Line Takes the Leadership - IS Management in a Wired Society. Sloan Management Review, Summer, pp. 57-64.

Reponen, T. (1994) Organisational information management strategies. Info Systems Journal 4, pp. 27-44. 
Ruohonen, M. (1991) Stakeholders of Strategic Information Systems Planning - theoretical concepts and empirical examples. The Journal of Strategic IS 1 (1), pp. 15-28.

Ruohonen, M.J. (1995) Stakeholder Thinking in Information Strategy Planning. In Näsi, J. (ed.) (1995) Understanding Stakeholder Thinking. Gummerus, Jyväskylä.

Sachs, P. (1995) Transforming Work: Collaboration, Learning, and Design. Communications of the ACM Vol. 38(9), pp. 36-44.

Scott-Morton, M.S. (ed.) (1991) The Corporation of the 1990's. Oxford University Press, New York.

Salmela, H. (1996) The Requirements for Information Systems Planning in a Turbulent Environment. Publications of the Turku School of Economics and Business Administration Series A-1:1996.

Stephens, C. S., Mitra, A., Ledbetter, W.N. \& Ford, F.N. (1994) The Strategic Planning Process for the Information Executive: Work Characteristics and Implications. Proceedings of the 1994 Southeast Decision Sciences Institute, Williamsburg, Va.

Stephens, C. S. (1995) The Nature of Information Technology Managerial Work - The Worklife of Five Chief Information Officers. Quorum Books, Westport, Connecticut.

Synnott, W.R. \& Gruber, W.H. (1981) Information Resource Management. New York, John Wiley \& Sons. 